University of Nebraska - Lincoln

DigitalCommons@University of Nebraska - Lincoln

Faculty Publications from the Harold W. Manter Laboratory of Parasitology

1988

\title{
GENETIC DIFFERENTIATION AND BIOCHEMICAL POLYMORPHISM AMONG TRICHOMONADS
}

Steven A. Nadler

University of California - Davis, sanadler@ucdavis.edu

B. M. Honigberg

University of Massachusetts - Amherst

Follow this and additional works at: https://digitalcommons.unl.edu/parasitologyfacpubs

Part of the Parasitology Commons

Nadler, Steven A. and Honigberg, B. M., "GENETIC DIFFERENTIATION AND BIOCHEMICAL

POLYMORPHISM AMONG TRICHOMONADS" (1988). Faculty Publications from the Harold W. Manter Laboratory of Parasitology. 701.

https://digitalcommons.unl.edu/parasitologyfacpubs/701

This Article is brought to you for free and open access by the Parasitology, Harold W. Manter Laboratory of at DigitalCommons@University of Nebraska - Lincoln. It has been accepted for inclusion in Faculty Publications from the Harold W. Manter Laboratory of Parasitology by an authorized administrator of DigitalCommons@University of Nebraska - Lincoln. 


\title{
GENETIC DIFFERENTIATION AND BIOCHEMICAL POLYMORPHISM AMONG TRICHOMONADS
}

\author{
Steven A. Nadler* and B. M. Honigberg $\dagger$ \\ Department of Zoology, Center for Parasitology, University of Massachusetts at Amherst, \\ Amherst, Massachusetts 01003-0027
}

ABSTRACT: Isoenzyme electrophoresis was used to study levels of genetic differentiation among strains and clones of Trichomonas gallinae, Trichomonas vaginalis, Tritrichomonas foetus, Tetratrichomonas gallinarum, and Pentatrichomonas hominis. Strain variation was found within T. gallinae, T. vaginalis, and T. foetus, however, levels of enzyme polymorphism were greater in $T$. gallinae than in $T$. vaginalis or $T$. foetus. Isoenzyme genotypes were not a stable property of $T$. gallinae clones cultivated in vitro. Retrospective studies of $T$. gallinae SG and JB6 clones revealed that mutation occurred during in vitro cultivation. Heterozygotes of hexokinase-1 and phosphoglucomutase displayed 2 allomorphs in equal dosage, indicating that trichomonads are diploid for these protein loci. Phenetic clustering of the biochemical data suggests that levels of genetic divergence among the species studied are extensive.

Isoenzyme electrophoresis has proven to be a useful tool for studying protozoan genetics and systematics (Carter, 1978; Gibson et al., 1980; Kreutzer and Sousa, 1981; Chapman, 1982; Moss et al., 1986; O'Donoghue et al., 1986). Previous isoenzyme studies of trichomonads have focused on conspecific variation in isoenzyme phenotypes (Chyle et al., 1971; Takayanagi et al., 1971; Soliman et al., 1982; Coombs and North, 1983; Gradus and Matthews, 1985), although congeneric and intergeneric differences in the mobilities of certain proteins have been occasionally noted. Unfortunately, genetic interpretations of electrophoretic phenotypes and comparisons of different taxa have been lacking. In addition, investigators have not tested for correlations between isoenzyme phenotypes and virulence, geographic distribution, or antigenic properties of trichomonads.

In the present study, isoenzyme data are presented for Trichomonas gallinae (Rivolta), Trichomonas vaginalis Donné, Tritrichomonas foetus (Riedmüller), Tetratrichomonas gallinarum (Martin and Robertson), and Pentatrichomonas hominis (Davaine). Levels of biochemical polymorphism and genetic divergence among the above taxa are described and discussed.

\section{MATERIALS AND METHODS}

\section{Organisms}

All trichomonads used in this investigation were grown from cryopreserved stabilates. The following

Received 21 October 1987; revised 15 April 1988; accepted 10 May 1988.

* Current address: Museum of Natural Science, Louisiana State University, Baton Rouge, Louisiana 70803-3216.

$\dagger$ To whom reprint requests should be addressed. genera, species, strains, and clones (cl) were used (geographic origin of stabilate in parentheses): $T$. gallinae Jones' Barn (JB) strain isolate 6 (Pennsylvania, U.S.A.), JB6 cl(s) 1, 7, and 8; Stabler-gallinae (SG) cl 1 (Colorado, U.S.A.), SG scl 1 (a subclone of SG cl 1); SGC cl 1 (derived from SG cl 1 by 12 mo of continuous in vitro cultivation); $T$. vaginalis $\mathrm{TvK} 1$ strain (isolated by Kupferberg and Trussell in 1939, U.S.A.), Balt strains 23, 41, 42, 44, 53, 55, 70, and 80 (Maryland, U.S.A.), Balt $42 \mathrm{cl}(\mathrm{s})$ 4, 5, 6, 7, 8, 9, and 11, Balt 44, cl(s) 4, 5, and 7, JH 31 A strain (Maryland, U.S.A.), JH 31 A, cl(s) 7, 8, and 10; $T$. foetus KV (Karlovy Vary, Czechoslovakia) cl 1 (KV-1), CB strain (Colorado, U.S.A.), UT (Utah, U.S.A.) cl 1 (UT-1), COLO cl 1 (Colorado, U.S.A.), and DK (California, U.S.A.) cl 2 (DK-2); $T$. gallinarum $\mathrm{cl} 1$ (Massachusetts, U.S.A.); $P$. hominis $\mathrm{cl}$ 1 (Korea). Methods of isolation and histories of most of these strains and clones have been previously documented (Honigberg, 1961; Honigberg et al., 1966, 1970, 1984; Kulda, 1967; Honigberg and Goldman, 1968; Kulda and Honigberg, 1969; Stepkowski and Honigberg, 1972; Kulda et al., 1974; Su-Lin and Honigberg, 1983). The IBERG strain of $T$. gallinae was isolated on 5 May 1980 from throat swabs of a pigeon obtained from Dr. R. M. Stabler (Colorado). This strain was transferred twice in Diamond's TYM, pH 7.0, containing $1,000 \mathrm{U}$ penicillin and $1,000 \mu \mathrm{g}$ streptomycin/ml, transferred to TYM without antibiotics, and cryopreserved. Infections with the IBERG strain are usually fatal for pigeons. Trichomonas gallinae SG scl 1 was obtained by subcloning from SG cl 1 during the course of this investigation. An attenuated strain of $T$. gallinae, JB6 cl 8 att (attenuation confirmed by pigeon inoculation), was obtained by maintaining virulent JB6 cl 8 in culture for 144 days. Tritrichomonas foetus isolates CB strain and COLO $\mathrm{cl} 1$ were both isolated from bulls in Colorado during 1967 and maintained as frozen stabilates.

\section{Cultivation}

All $T$. vaginalis strains and clones were grown in Diamond's trypticase-yeast-maltose medium (TYM) (Diamond, 1957), pH 6.0, supplemented with $10 \%$ $\mathrm{v} / \mathrm{v}$ heat-inactivated horse serum. Stabilates were first cultivated in TYM and were subsequently transferred to TYM without agar. Trichomonas gallinae, T. foetus, 
TABLE I. Enzymes resolved in the trichomonad taxa.

\begin{tabular}{lll}
\hline $\begin{array}{c}\text { Abbrevi- } \\
\text { ation }\end{array}$ & \multicolumn{1}{c}{ Enzyme } & E.C. No. \\
\hline ACP & Acid phosphatase & 3.1 .3 .2 \\
ALD & Fructose-biphosphate aldolase & 4.1 .2 .13 \\
G6PD & Glucose-6-phosphate dehydrogenase & 1.1 .1 .49 \\
HI & Phosphohexose isomerase & 5.3 .1 .9 \\
HK-1 & Hexokinase-1 & 2.7 .1 .1 \\
HK-2 & Hexokinase-2 & 2.7 .1 .1 \\
LDH & Lactate dehydrogenase & 1.1 .1 .27 \\
PEP-B & Leucyl-glycyl-glycine peptidase & 3.4 .11 .13 \\
MDH-1 & Malate dehydrogenase-1 & 1.1 .1 .37 \\
MDH-2 & Malate dehydrogenase-2 & 1.1 .1 .37 \\
PGM & Phosphoglucomutase & 5.4 .2 .2 \\
UAE & Umbelliferyl acetate esterase & 3.1 .1 .1 \\
\hline
\end{tabular}

$T$. gallinarum, and $P$. hominis were grown in cysteinetryptose-liver-maltose medium (CTLM) (McEntegart, 1952), pH 7.3, or Diamond's TYM, pH 7.0 (modified by substituting BBL trypticase peptone for trypticase), media without agar, supplemented with $10 \%$ heat-inactivated horse serum. Log-phase trichomonads were harvested by centrifugation and subsequently washed 3 times in 10 volumes of an ice-cold homogenizing solution containing $6 \mathrm{~g}$ sucrose and $10 \mathrm{mg}$ each of dithiothreitol, $\beta$-NAD, and $\beta$-NADP $/ 100 \mathrm{ml}$ of distilled water. Washed organisms were pelleted at 11,600 $g$ and frozen at $-70 \mathrm{C}$. Frozen samples were used within 3 mo of the time of harvest.

\section{Electrophoresis}

Immediately before use, cell pellets were thawed, suspended in 2 volumes of homogenizing solution, and disrupted using either a probe sonicator or a Dounce homogenizer. Homogenates were centrifuged at 11,600 $g$ for $3 \mathrm{~min}$ to remove cell debris, and samples of the supernatant fluid were subjected to vertical starch gel electrophoresis at $4 \mathrm{C}$. The following buffers were used for electrophoresis: (a) phosphate-citrate, $\mathrm{pH} 6.8$ (60 $\mathrm{mM} \mathrm{Na}_{2} \mathrm{HPO}_{4} 10 \mathrm{mM}$ citric acid) diluted 1:4 for gel and undiluted for electrode bath; (b) Tris-maleate, $\mathrm{pH}$ 7.5 (100 mM Tris adjusted to $\mathrm{pH} 7.5$ with $2 \mathrm{M}$ maleic acid) diluted 1:3 for gel and undiluted for electrode bath.

\section{Enzyme localization}

Following electrophoresis, proteins were visualized in gel slices by procedures described in Harris and Hopkinson (1976). Acid phosphatase was detected by the method of El-Sharkawy and Huisingh (1971). See Table I for enzymes resolved, their abbreviations, and Enzyme Commission numbers. Control gel slices developed without the corresponding specific substrates (e.g., lactate dehydrogenase without sodium lactate), yielded no detectable stain reactions.

Differences in phenotypes at a specific locus were used to deduce genotypes of clones or the number of allomorphs occurring in noncloned strains. For each locus, the allomorph of fastest anodal mobility was designated $\mathrm{A}$; then, the others in order of decreasing mobilities, as B, C, etc. When more than 1 presumed locus yielded products with the same enzymatic activity, the locus with isozymes of faster anodal mobility was designated 1 and that of slower mobility as 2 .

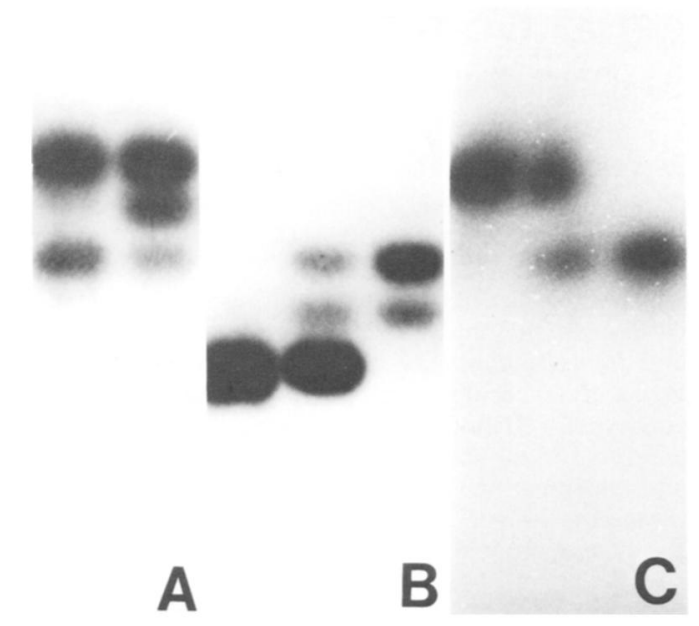

Figure 1. Phenotypes of some polymorphic trichomonad enzymes. The anode is at the top. Taxa and their presumed genotypes (in italics) are read left to right. Methods of allomorph designation are described in the Materials and Methods. A. Hexokinase loci (HK) 1 and 2. Trichomonas gallinae JB6 cl 7, HK-1 CC, HK-2 CC; T. gallinae JB6 cl 1, 1985 stabilate, HK-1 $C D, \mathrm{HK}-2 C C$. The HK-1 heterozygote has 2 bands with a 1:1 staining intensity, indicating a monomeric subunit structure. B. Phosphoglucomutase (PGM). T. gallinae JB6 cl 7, PGM DD; T. gallinae JB6 cl 1,1985 stabilate, PGM $B C D ; T$. gallinae $\mathrm{SGC}$ cl 1 , PGM $B C$. Heterozygote phenotype characteristic of a monomeric protein. C. Leucyl-glycyl-glycine peptidase (PEP-B). Pentatrichomonas hominis cl 1, PEP-B $A A$; Trichomonas vaginalis Balt 80 , PEP-B $A B ; T$. gallinae IBERG, PEP-B $B B$.

\section{Data analysis}

The BIOSYS-1 computer program (Swofford and Selander, 1981) was used to analyze genetic data and produce the UPGMA phenogram. Clustering procedures were performed using only those 9 loci that were scored in all species (i.e., excluding the proteins acid phosphatase, lactate dehydrogenase, and umbelliferyl acetate esterase in Table II).

\section{RESULTS}

Representative isoenzyme phenotypes and their corresponding genotypes are shown in Figure 1. Additional enzymes that showed activity on gel slices, but were not adequately resolved for interpretation included: glutamate-oxaloacetate transaminase, glutamate dehydrogenase, $\alpha$-naphthyl acetate esterase, superoxide dismutase, and catalase. In a few instances, a protein resolved in one species or strain lacked sufficient activity to be interpreted in another. In other cases, a protein with more than 1 locus in one species sometimes showed only a single activity zone in another. In such instances, the single 
zone of activity was considered to be composed of 2 comigrating loci.

Malate dehydrogenase- 1 and -2 were the only loci with more than 1 phenotype in $T$. foetus, and they served to distinguish $\mathrm{KV}-1$ from the other strains and clones. Polymorphic loci in $T$. gallinae included: hexokinase-1, hexokinase-2, phosphoglucomutase, malate dehydrogenase-1, and malate dehydrogenase-2. Heterozygotes were observed for $T$. gallinae hexokinase- 1 and phosphoglucomutase only (Fig. 1A, B). Polymorphic loci in $T$. vaginalis were restricted to phosphoglucomutase and leucyl-glycyl-glycine peptidase (Fig. 1C) in Balt 41 and Balt 80 strains, respectively. This was the only protein variation detected among the 23 stabilates of this species examined in the present study. These stabilates represented 9 strains, 13 clones obtained from these strains, and 1 strain (TvK1) that was isolated in 1939.

Studies of extant clones of T. gallinae JB6 indicate that they are not genetically identical (Table II). For example, JB6 cl 1 has a CD genotype for hexokinase-1, whereas JB6 clones 7 and 8 have a $\mathrm{CC}$ genotype at this locus. The parent strain of these clones, JB6, also has a CC hexokinase- 1 genotype and is identical to clones 7 and 8 at all other loci. This suggests that either the $\mathrm{D}$ allomorph was lost from the parent strain subsequent to cloning, or that a new allomorph is being expressed in JB6 $\mathrm{cl} \mathrm{1.} \mathrm{In} \mathrm{support} \mathrm{of} \mathrm{the}$ second explanation, retrospective studies revealed that isolates of JB6 $\mathrm{cl} 1$ and SG $\mathrm{cl} 1$ have undergone genetic changes during in vitro cultivation. For example, a 1970 stabilate of JB6 cl 1 yielded a homozygous DD phosphoglucomutase genotype, however, a 1985 stabilate of the same clone yielded a BCD phosphoglucomutase phenotype with a complex gene dosage (Fig. 1B). In the case of SG $\mathrm{cl} \mathrm{1}$, stabilates of the original clone yielded a BCD phosphoglucomutase phenotype, indicating that this was not a successful clone, but instead a mixed population. This was substantiated by subcloning, which yielded SG scl 1 with a DD phosphoglucomutase genotype. In contrast to the situation with $\mathrm{JB} 6 \mathrm{cl} \mathrm{1}$, prolonged cultivation of $\mathrm{SG}$ cl 1 (i.e., SGC cl 1) produced a normal dosage phosphoglucomutase BC genotype (Fig. 1B).

The number and relative staining intensity of isozyme bands in clones heterozygous for individual protein loci were used to deduce the subunit structures of those enzymes. Heterozygotes of hexokinase-1 and phosphoglucomutase dis- played 2 bands of equal staining intensity, indicating that these proteins are monomers (Fig. 1A, B).

Some trichomonad strains can be conclusively diagnosed from their isoenzyme phenotypes ( $\mathrm{Ta}$ ble II). Among $T$. gallinae strains, the hexokinase-2 locus " $C$ " allele distinguishes the virulent $\mathrm{JB}$ and IBERG strains from the avirulent SG strain. In addition, the highly virulent $T$. foetus $\mathrm{KV}-1$ isolate can be distinguished from those clones and strains of intermediate and low virulence (DK-2, CB, UT-1, and COLO cl 1) by the malate dehydrogenase- 1 and malate dehydrogenase-2 loci. In contrast, no differentiating allomorphs were detected among $T$. vaginalis Balt strains that differed in their inherent virulence as previously evaluated on the basis of the pathologic changes they caused in women, and by the subcutaneous mouse assay (Honigberg et al., 1984). Finally, a stabilate of $T$. gallinae JB6 cl 8 , which was virulent for pigeons, had an isoenzyme profile identical to a stabilate of JB6 $\mathrm{cl} 8$ that had been attenuated by 144 days of in vitro cultivation.

A matrix of Rogers' (1972) genetic similarity and Nei's (1972) genetic distance coefficients among representative taxa are presented in Table III. Pairwise comparisons of species yielded extremely low genetic similarity levels. Phenetic clustering (UPGMA) of the genetic data (Fig. 2) produced 3 major groups. Pentatrichomonas hominis showed the lowest level of genetic similarity to the other trichomonad taxa. The 2 urogenital species of mammals (Trichomonas vaginalis and Tritrichomonas foetus) and the 2 gastrointestinal species from birds (Trichomonas gallinae and Tetratrichomonas gallinarum) clustered as 2 distinct groups. Within $T$. gallinae, the 2 isolates from Colorado (IBERG and SG $\mathrm{cl} \mathrm{1)}$ showed low levels of genetic similarity in comparison to the isolate from Pennsylvania (JB6).

\section{DISCUSSION}

Differences in levels of enzyme polymorphism were found between Trichomonas gallinae and Trichomonas vaginalis. Five of 11 loci surveyed were polymorphic in $T$. gallinae, but only 2 of 11 loci were polymorphic in $T$. vaginalis. Two polymorphic loci were detected in Tritrichomonas foetus, however, only 5 stabilates representing 5 strains were surveyed. Alderete (1983) also reported homogeneity in the protein profiles of 5 strains of $T$. vaginalis analyzed by SDSPAGE. The level of $T$. vaginalis enzyme poly- 
TABLE II. Electrophoretic genotypes in trichomonad taxa.*

Trichomonas gallinae

\begin{tabular}{llccccccc} 
Locus & JB6 & $\begin{array}{c}\text { JB6 cl(s) 7, 8 } \\
\text { JB6 cl 8 (att) }\end{array}$ & $\begin{array}{c}\text { JB6 cl 1 } \\
(1970)\end{array}$ & $\begin{array}{c}\text { JB6 cl 1 } \\
(1985)\end{array}$ & IBERG & SG cl 1 & SG scl 1 & SGC cl 1 \\
\hline ACP & n/a & n/a & n/a & n/a & n/a & n/a & n/a & n/a \\
ALD & DD & DD & DD & DD & DD & DD & DD & DD \\
G6PD & BB & BB & BB & BB & BB & BB & BB & BB \\
HI & CC & CC & CC & CC & CC & CC & CC & CC \\
HK-1 & CC & CC & CD & CD & CC & CD & CC & DD \\
HK-2 & CC & CC & CC & CC & CC & DD & DD & DD \\
PEP-B & BB & BB & BB & BB & BB & BB & BB & n/a \\
MDH-1 & BB & BB & BB & BB & AA & AA & AA & AA \\
MDH-2 & DD & DD & DD & DD & BB & BB & BB & BB \\
PGM & DD & DD & DD & BCD & DD & BCD & DD & BC \\
UAE & n/a & BB & n/a & n/a & n/a & n/a & n/a & n/a \\
LDH & AA & AA & AA & AA & AA & AA & AA & na \\
\hline
\end{tabular}

* Locus abbreviations are indicated in Table $\mathrm{I} ; \mathrm{n} / \mathrm{a}=$ no activity detected.

morphism observed in the present study conflicts with the results of Soliman et al. (1982), who reported variation in 4 enzymes (lactate dehydrogenase, malate dehydrogenase, hexokinase, and phosphohexose isomerase) among clones derived from 32 strains of $T$. vaginalis. These 4 loci were monomorphic in the strains of $T$. vaginalis we studied. Limited variability at the phosphoglucomutase locus was detected by Soliman et al. (1982) and in the present investigation. Clearly, enzyme polymorphism in the $T$. vaginalis isolates we examined was considerably lower than that found by Soliman et al. (1982) or by us for $T$. gallinae. At this time, explanations for such differences remain speculative; however, some possibilities merit discussion. First, the isolates we studied may not be representative of the genetic variability present in $T$. vaginalis. All of the strains and clones we surveyed, except for TvK1, were obtained from patients attending the Johns Hopkins Hospital Gynecologic or Obstetric Clinics in Baltimore, Maryland, U.S.A. A comparison of strains isolated from women residing in distant geographic localities may reveal additional variation. Second, very little is known about what effects in vitro cultivation has on the genetic composition of isolates. Culture medium could act as a highly selective environment, or conversely, an unrestrictive one, which supports the growth of mutants that would not normally survive in vivo. One possibility is that $T$. gallinae, which usually grows more vigorously than $T$. vaginalis in vitro, may experience less selection pressure or fewer population bottlenecks than $T$. vaginalis upon initial isolation. Thus, variability of in vivo strains of $T$. gallinae may be better preserved upon in vitro isolation. It should also be noted that differences at the hexokinase-1 locus between JB6 clone 1 (1970) and clones 7 and 8 may reflect allomorphic variation that was once present in the parent strain from which these clones were derived. Isoenzyme variation among clones of Trypanosoma cruzi derived from a single parental stock has been reported (Goldberg and Silva Pereira, 1983).

This investigation also demonstrates that isoenzyme genotypes are not stable attributes of in vitro-cultivated $T$. gallinae. From the observations with $T$. gallinae JB6 clones, it appears that in vitro mutation influences the extant isoenzyme phenotypes of clones. For example, following an undefined period of in vitro cultivation, JB6 cl 1 began expressing a phosphoglucomutase allomorph that was not detected in cultures prepared from the 1970 stabilate of that clone. This allomorph, which was also found in other clones of JB6, probably originated by mutation. Changes in isoenzyme patterns and virulence during axenization of Entamoeba histolytica have also been reported (Mirelman et al., 1986).

Changes in the composition of $T$. gallinae populations were observed with SG "clone 1." Isoenzyme study revealed that cultures inoculated with the original SG cl 1 stabilate had a complex BCD phosphoglucomutase phenotype, which implies that it was not a clone, but rather a mixed population. This was substantiated by the subclone SG scl 1 that had a homozygous DD phosphoglucomutase genotype. Only by additional subcloning from SG cl 1 could it be ascertained 
TABLE II. Extended.

\begin{tabular}{|c|c|c|c|c|c|c|}
\hline \multirow[b]{4}{*}{ Balt 41} & \multicolumn{2}{|l|}{ Trichomonas vaginalis } & \multirow{2}{*}{\multicolumn{2}{|c|}{ Tritrichomonas foetus }} & \multirow{4}{*}{$\begin{array}{c}\begin{array}{c}\text { Pentatricho- } \\
\text { monas hominis }\end{array} \\
\text { cl } 1\end{array}$} & \multirow{4}{*}{$\begin{array}{c}\begin{array}{c}\text { Tetratricho- } \\
\text { monas gallinarum }\end{array} \\
\mathrm{cl} \mathrm{l}\end{array}$} \\
\hline & \multirow{3}{*}{$\begin{array}{l}\text { Balt } 42 \mathrm{cl}(\mathrm{s}), 4,6,7,8,9,11 \\
\text { Balt } 23,42,44,53,55,70 \\
\text { Balt } 44 \mathrm{cl}(\mathrm{s}) 4,5,7 \\
\mathrm{JH} 31-4 \\
\mathrm{JH} 31-4 \mathrm{cl}(\mathrm{s}) 1,3,5 \\
\text { TvKl }\end{array}$} & \multirow[b]{3}{*}{ Balt 80} & & & & \\
\hline & & & \multirow[b]{2}{*}{$\mathrm{KV}-1$} & \multirow{2}{*}{$\begin{array}{l}\text { COLO cl } 1 \\
\text { CB } \\
\text { DK-2 } \\
\text { UT-1 }\end{array}$} & & \\
\hline & & & & & & \\
\hline BB & BB & $\mathbf{n} / \mathbf{a}$ & $\mathrm{n} / \mathrm{a}$ & $\mathbf{n} / \mathbf{a}$ & AA & AA \\
\hline DD & DD & DD & AA & AA & $\mathrm{CC}$ & BB \\
\hline $\mathbf{A A}$ & AA & AA & $\mathrm{CC}$ & $\mathbf{n} / \mathbf{a}$ & $\mathrm{CC}$ & $\mathrm{CC}$ \\
\hline BB & BB & BB & DD & DD & AA & $\mathrm{CC}$ \\
\hline $\mathrm{EE}$ & $\mathrm{EE}$ & $\mathrm{EE}$ & AA & AA & BB & DD \\
\hline EE & EE & EE & AA & AA & BB & FF \\
\hline BB & BB & $\mathbf{A B}$ & BB & $\mathbf{n} / \mathbf{a}$ & AA & BB \\
\hline BB & BB & BB & BB & $\mathrm{CC}$ & DD & AA \\
\hline $\mathrm{CC}$ & $\mathrm{CC}$ & $\mathrm{CC}$ & $\mathrm{CC}$ & $\mathrm{EE}$ & FF & AA \\
\hline AB & BB & BB & AA & AA & AA & DD \\
\hline $\mathrm{n} / \mathrm{a}$ & $\mathrm{n} / \mathrm{a}$ & $\mathbf{n} / \mathbf{a}$ & AA & $\mathrm{n} / \mathrm{a}$ & $\mathbf{n} / \mathbf{a}$ & $\mathrm{n} / \mathrm{a}$ \\
\hline CC & $\mathrm{CC}$ & $\mathrm{CC}$ & $\mathbf{n} / \mathbf{a}$ & $\mathrm{n} / \mathrm{a}$ & BB & $\mathrm{CC}$ \\
\hline
\end{tabular}

how many other genotypically distinct populations are present within this culture. Interestingly, during 12 mo of in vitro cultivation, SG cl 1 phosphoglucomutase and hexokinase- 1 phenotypes changed. As can be seen from the SGC cl 1 data (Table II), the SG cl 1 mixed population became monomorphic for hexokinase- 1 and "heterozygous" for phosphoglucomutase. In this case, no new allomorphs were expressed, and it is unknown whether a subpopulation containing the other allomorphs remains as a hidden component of the SGC $\mathrm{cl} 1$ population.

Within Trichomonas gallinae and Tritrichomonas foetus, some strains could be definitively diagnosed on the basis of their isoenzyme phenotypes. For example, T. gallinae SG, IBERG, and JB6 strains can be differentiated from one another. In addition, the strains and clones of $T$. gallinae that were isolated from virulent stocks differed in their hexokinase- 2 genotype from the avirulent SG clones. Tritrichomonas foetus KV1 has malate dehydrogenase mobility differences that differentiate it from all other strains of this species examined. These malate dehydrogenase allomorphs differentiate the highly virulent $T$. foetus $\mathrm{KV}-1$ isolate from moderately virulent and avirulent strains and clones. However, for both $T$. gallinae and $T$. foetus, a limited number of strains with known virulence levels have been examined, and therefore it is premature to conclude that these genetic markers are correlated with virulence. Unfortunately, isoenzymes did not differentiate among $T$. vaginalis strains that varied considerably in their inherent pathogenicity (Honigberg et al., 1984).

The UPGMA phenogram (Fig. 2) shows the relative degree of genetic differentiation among the taxa examined by us, and should not be interpreted as representing phylogenetic relationships. Rogers' (1972) genetic similarity coefficients among these taxa are very low, which suggests that times of divergence among these taxa are ancient. Phenetic clustering of the genetic data results in associations that are discor-

TABLE III. Matrices of Rogers' similarity values (above the diagonal) and Nei's distance coefficients (below the diagonal) for representative trichomonad taxa.

\begin{tabular}{llcccccccccc}
\hline \multicolumn{1}{c}{ Taxon } & 1 & 2 & 3 & 4 & 5 & 6 & 7 & 8 & 9 & 10 \\
\hline 1 Trichomonas gallinae JB6 & - & 0.944 & 0.778 & 0.667 & 0.348 & 0.333 & 0.278 & 0.333 & 0.0 & 0.222 \\
2 & Trichomonas gallinae JB6 cl 1 1970 & 0.029 & - & 0.722 & 0.611 & 0.363 & 0.348 & 0.293 & 0.389 & 0.015 & 0.237 \\
3 Trichomonas gallinae IBERG & 0.251 & 0.297 & - & 0.889 & 0.237 & 0.222 & 0.167 & 0.444 & 0.0 & 0.111 \\
4 & Trichomonas gallinae SGcl 1 & 0.405 & 0.464 & 0.118 & - & 0.237 & 0.222 & 0.167 & 0.444 & 0.0 & 0.111 \\
5 Trichomonas vaginalis BALT 41 & 1.070 & 1.041 & 1.475 & 1.475 & - & 0.944 & 0.889 & 0.126 & 0.056 & 0.389 \\
6 Trichomonas vaginalis BALT 42 & 1.099 & 1.070 & 1.504 & 1.504 & 0.029 & - & 0.944 & 0.111 & 0.0 & 0.333 \\
7 Trichomonas vaginalis BALT 80 & 1.252 & 1.224 & 1.763 & 1.763 & 0.061 & 0.029 & - & 0.056 & 0.056 & 0.278 \\
8 Trichomonas gallinarum cl 1 & 1.099 & 0.916 & 0.811 & 0.811 & 2.169 & 2.197 & 2.862 & - & 0.111 & 0.222 \\
9 Pentatrichomonas hominis cl 1 & & & & & 2.862 & & 2.862 & 2.197 & - & 0.222 \\
10 Tritrichomonas foetus KV 1 & 1.504 & 1.475 & 2.197 & 2.197 & 0.916 & 1.099 & 1.252 & 1.504 & 1.504 & - \\
\hline
\end{tabular}




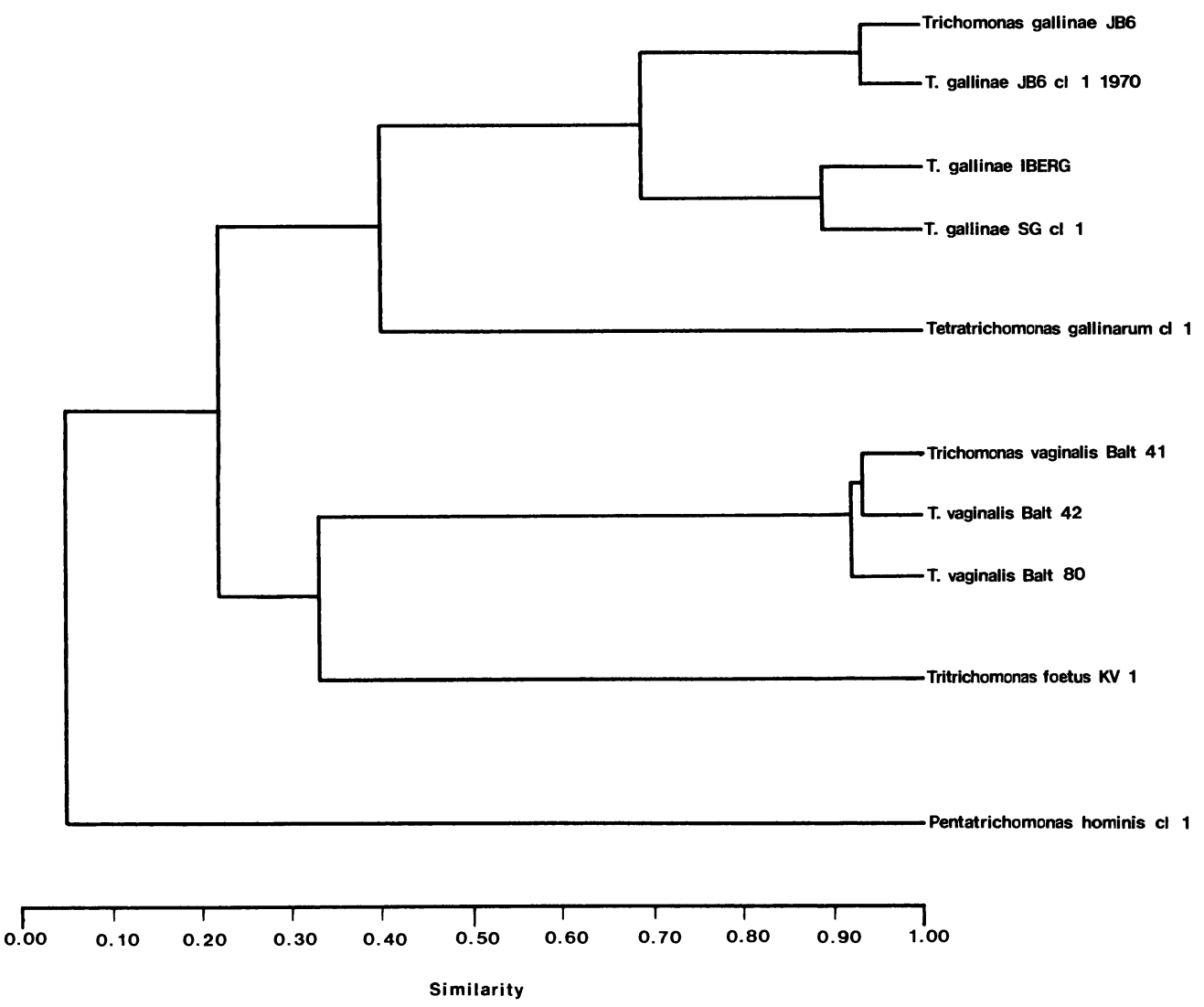

FIGURE 2. Phenogram of genetic differentiation among representative trichomonad taxa. Rogers' similarity metric was clustered by the UPGMA method. The cophenetic correlation coefficient for the phenogram is 0.966 .

dant with both alpha-taxonomy and limited immunological data (Honigberg, 1978; Stepkowski and Honigberg, 1981). For example, the congeners $T$. gallinae and $T$. vaginalis do not cluster together in the phenogram, but instead are grouped with Tetratrichomonas gallinarum and Tritrichomonas foetus, respectively. It is noteworthy that phenetic clustering of the genetic data places the 2 urogenital species from mammals and the 2 species from the digestive tract of birds into 2 distinct groups. However, the low levels of genetic similarity among the species studied indicate that studies of more conservative molecules may be required to clarify the phylogenetic relationships in this group. Finally, the low levels of genetic similarity between $T$. gallinae strains isolated in Colorado and Pennsylvania suggest that there may be significant geographic variation in this species.

Subunit structures of the proteins hexokinase-1 and phosphoglucomutase in $T$. gallinae correspond to those of a phylogenetically diverse array of animals (Dessauer and Braun, 1982), as do those of other protozoa (Chapman et al., 1984). The expression of 2 allomorphs in equal dosage as observed in heterozygous clones suggests that trichomonads are diploid for these protein loci. However, this does not necessarily imply that they are chromosomally diploid. Studies of a similar nature have led investigators to conclude that Trypanosoma cruzi (Tibayrenc et al., 1981; Miles, 1983) and Trypanosoma brucei (Gibson et al., 1985; Jenni et al., 1986) are also diploid at many loci coding for enzymatic proteins.

Difficulties in resolving certain loci in some trichomonad taxa (see also Soliman et al., 1982) have many potential causes. No lactate dehydrogenase activity was found in $T$. foetus strains, however a recent report (Steinbuchel and Muller, 1986) indicates that this species does not produce lactate as a metabolic end product. Some enzymatic activities, hexokinase- 2 in $T$. vaginalis for example, were lost relatively rapidly following homogenization. Presumably this locus and cer- 
tain others were either thermolabile or susceptible to proteinases released on homogenization (Coombs and North, 1983). Activation of trichomonad proteases by dithiothreitol in the homogenizing fluid may also have contributed to the observed reduction of some enzymatic activities.

\section{ACKNOWLEDGMENT}

This investigation was supported by Training Grant 5 T32 AIO7109-09 from the National Institute of Allergy and Infectious Diseases, U.S. Public Health Service (to B.M.H.).

\section{LITERATURE CITED}

Alderete, J. F. 1983. Antigen analysis of several pathogenic strains of Trichomonas vaginalis. Infection and Immunity 39: 1041-1047.

CARTER, R. 1978. Studies on enzyme variation in murine malaria parasites $P$. berghei, $P$. yoelii, $P$. vinckei and $P$. chabaudi by starch gel electrophoresis. Parasitology 76: 241-267.

Chapman, H. D. 1982. The use of enzyme electrophoresis for identification of the species of Eimeria present in field isolates of coccidia. Parasitology 85: 437-442.

Chapman, M. D., A. Caffery, M. A. Miles, and D. M. Swallow. 1984. Enzyme subunit numbers in Trypanosoma cruzi zymodemes. Annals of Tropical Medicine and Parasitology 78: 541-542.

Chyle, M., J. Stepan, P. Chyle, and F. Patocka. 1971. Some enzymes and isoenzyme activities in Trichomonas vaginalis. Folia Microbiologica 16: 142-143.

COOMBS, G. H., AND M. J. NorTh. 1983. An analysis of the proteinases of Trichomonas vaginalis by polyacrylamide gel electrophoresis. Parasitology 86: $1-6$.

Dessauer, H. C., AND M. J. Braun. 1982. Abstracts of the fourth international congress on isozymes, Austin, Texas.

Diamond, L. S. 1957. The establishment of various trichomonads of animals and man in axenic cultures. Journal of Parasitology 43: 488-490.

El-Sharkawy, T. D., AND D. Huisingh. 1971. Differentiation among Xanthomonas species by polyacrylamide gel electrophoresis of soluble proteins. Journal of General Microbiology 68: 155-165.

Gibson, W. C., T. F. MARShall, AND D. G. Godfrey. 1980. Numerical analysis of enzyme polymorphism: A new approach to the epidemiology and taxonomy of trypanosomes of the subgenus Trypanozoon. Advances in Parasitology 18: 175-246.

, K. A. Osinga, P. A. M. Michels, and P. BoRsT. 1985. Trypanosomes of subgenus Trypanozoon are diploid for housekeeping genes. Molecular and Biochemical Parasitology 16: 231-242.

Goldberg, S. S., AND A. A. Silva Pereira. 1983. Enzyme variation among clones of Trypanosoma cruzi. Journal of Parasitology 69: 91-96.

Gradus, M. S., AND H. M. MatThews. 1985. Electrophoretic analysis of soluble proteins and ester- ase, superoxide dismutase and acid phosphatase isoenzymes of members of the protozoan family Trichomonadidae. Comparative Biochemistry and Physiology 81B: 229-233.

HARRIS, H., AND D. A. HoPKINSON. 1976. Handbook of enzyme electrophoresis in human genetics. North-Holland Publishing Company, Amsterdam.

HoNigBeRG, B. M. 1961. Comparative pathogenicity of Trichomonas vaginalis and Trichomonas gallinae to mice. I. Gross pathology, quantitative evaluation of virulence, and some factors affecting pathogenicity. Journal of Parasitology 47: 545-571. . 1978. Trichomonads of veterinary importance. In Parasitic protozoa, Vol. II, J. P. Kreier (ed.). Academic Press, New York, pp. 163-273.

, AND M. Goldman. 1968. Immunologic analysis by quantitative fluorescent antibody methods of the effects of prolonged cultivation on Trichomonas gallinae. Journal of Protozoology 15: 176184.

, P. K. Gupta, M. R. Spence, J. K. Frost, K. KuCZYNSKa, L. ChOROMANSKI, AND A. WARTON. 1984. Pathogenicity of Trichomonas vaginalis: Cytopathologic and histopathologic changes of the cervical epithelium. Obstetrics and Gynecology 64: 179-184.

, M. C. Livingston, AND J. K. Frost. 1966. Pathogenicity of fresh isolates of Trichomonas vaginalis: The "mouse assay" versus clinical and pathologic findings. Acta Cytologica 10: 353-361. , R. M. Stabler, M. C. Livingston, AND J. KULDA. 1970. Further observations on the effects of various laboratory procedures on the virulence of Trichomonas gallinae for pigeons. Journal of Parasitology 56: 701-708.

Jenni, L., S. Marti, H. Schweizer, B. Betschart, R. W. F. Le Page, J. M. Wells, A. Tait, P. PaindavoIne, E. PAYS, AND M. SteInert. 1986. Hybrid formation between African trypanosomes during cyclical transmission. Nature 322: 173-175.

Kreutzer, R. D., AND O. E. Sousa. 1981. Biochemical characterization of Trypanosoma spp. by isozyme electrophoresis. American Journal of Tropical Medicine and Hygiene 30: 308-317.

KuLDA, J. 1967. Effect of different species of trichomonads on monkey kidney cell cultures. Folia Parasitologica 14: 295-310.

- AND B. M. HonigBerg. 1969. Behavior and pathogenicity of Tritrichomonas foetus in chick liver cell cultures. Journal of Protozoology 16: 479495.

- E. Suchankova, and S. Svoboda. 1974. Studies on pathogenicity of Tetratrichomonas gallinarum in mice and turkey polts. Acta Veterinaria (Brno) 43: 53-64.

MCENTEGART, M. G. 1952. The application of a haemagglutination technique to the study of Trichomonas vaginalis infections. Journal of Clinical Pathology 5: 275-280.

Miles, M. A. 1983. The epidemiology of South American trypanosomiasis-Biochemical and immunological approaches and their relevance to control. Transactions of the Royal Society of Tropical Medicine and Hygiene 77: 5-23. 
Mirelman, D., R. Bracha, A. Chayen, A. AustKeTtis, AND L. S. DiAmond. 1986. Entamoeba histolytica: Effect of growth conditions and bacterial associates on isoenzyme patterns and virulence. Experimental Parasitology 62: 142-148.

Moss, D. M., G. R. Healy, J. W. Dickerson, AND H. M. MAtHEWS. 1986. Isoenzyme analysis of $\mathrm{Ba}$ besia microti infections in humans. Journal of Protozoology 33: 213-215.

NEI, M. 1972. Genetic distance between populations. American Naturalist 106: 283-292.

O'Donoghue, P. J., M. Adams, B. R. Dixon, G. E. FORD, AND P. R. BAVERSTOCK. 1986. Morphological and biochemical correlates in the characterization of Sarcocystis spp. Journal of Protozoology 33: 114-121.

ROGERS, J. S. 1972. Measures of genetic similarity and genetic distance. Studies in Genetics, University of Texas Publications 7213: 145-153.

Soliman, M. A., J. P. Ackers, AND R. D. Catterall. 1982. Isoenzyme characterisation of Trichomonas vaginalis. British Journal of Venereal Diseases 58: $250-256$.

SteinbuChel, A., AND M. Muller. 1986. Glycerol, a metabolic end product of Trichomonas vaginalis and Tritrichomonas foetus. Molecular and Biochemical Parasitology 20: 45-55.
STEPKOWSKI, S., AND B. M. HoNigBERG. 1972. Antigenic analysis of virulent and avirulent strains of Trichomonas gallinae by gel diffusion methods. Journal of Protozoology 19: 306-315.

, AND - 1981. Antigenic analysis of some strains of the subfamily Trichomonadinae. Wiadomosci Parazytologiczne 29: 209-211.

Su-Lin, K.-E., AND B. M. Honigberg. 1983. Antigenic analysis of Trichomonas vaginalis strains by quantitative fluorescent antibody methods. Zeitschrift für Parasitenkunde 69: 161-181.

Swofford, D. L., AND R. B. SElander. 1981. BIOSYS-1: A FORTRAN program for the comprehensive analysis of electrophoretic data in population genetics and systematics. Journal of Heredity 72: 281-283.

TAKayanagi, T., G. L. EnRiouez, and H. Kambara. 1971. An electrophoretic study of the amylase of Trichomonas vaginalis. Southeast Asian Journal of Tropical Medicine and Public Health 2: 308312.

Tibayrenc, M., M. L. Cariou, and M. Solignac. 1981. Interpretation génétique des zymogrammes de flagellés des génres Trypanosoma et Leishmania. Comptes Rendus de l'Académie des Sciences, Paris 292: 623-625. 